Western University

Scholarship@Western

$12-4-2020$

\title{
"It's all window dressing:" Canadian police officers' perceptions of mental health stigma in their workplace
}

Lesley J. Bikos

University of Western Ontario, levans8@uwo.ca

Follow this and additional works at: https://ir.lib.uwo.ca/sociologypub

Part of the Sociology Commons

\section{Citation of this paper:}

Bikos, L.J. (2020), "'It's all window dressing:" Canadian police officers' perceptions of mental health stigma in their workplace", Policing: An International Journal, Vol. ahead-of-print No. ahead-of-print. https://doi.org/10.1108/PIJPSM-07-2020-0126 


\title{
"It's all Window Dressing:" Canadian Police Officers' Perceptions of Mental Health Stigma in their Workplace
}

\author{
Lesley J. Bikos \\ Department of Sociology, Western University, London, Canada
}

Purpose: This study will provide a preliminary, general overview of Canadian police officers' perception of stigma toward mental illness in their workplace culture and its impacts.

Design/methodology/approach: This study uses a mixed methods approach with two nationwide datasets: a self-report survey $(\mathrm{N}=727)$ and 116 semi-structured interviews with police officers from 31 police services. Results are grounded in theories of stigma, masculinities, and organizational culture.

Findings: Results indicate that most officers believe stigma toward mental illness in their workplace remains, despite senior management messaging and program implementation. Reporting mental illness was often seen as high risk, both personally and professionally. Policewomen, constables, and those on leave reported statistically significant higher levels of perceived stigma and risk. Features of traditional masculinity were commonly reported, influencing the way individuals viewed themselves (self-stigma) and organizational response (structural stigma). Those with lived experience reported the highest levels of self and structural stigmatization, which often negatively impacted their recovery.

Originality: This study strengthens our understanding of how organizational culture and structure combine to contribute to the persistent presence of stigma in some Canadian police services (with implications for male-dominated occupations generally). Gender, rank, years of service, and lived experience are additional areas of limited scholarship addressed by this study. The findings have important implications for effective program and policy evaluation and development.

Key Words: police culture, police officer mental health, stigma, masculinities, mixed methods

Police work is stressful, putting officers at a higher risk for mental illness and suicide than the general public (Carleton et al., 2018; Violenti et al., 2017). First responder mental illness has been deemed a crisis in Canada that requires more scholarship to better understand its prevalence, impact, and effective solutions (Oliphant, 2016). Police organizational culture is often described as a male-dominant environment with traditionally masculine traits such as stoicism and a tough, 'suck it up' attitude (Bulloch and Garland, 2017). When this type of culture is present, the perception of stigma toward mental illness is high, creating barriers to helpseeking (Karaffa and Koch, 2016; Stuart, 2017). Left untreated, mental illness can have multiple poor outcomes such as lost productivity and higher sick time; negative impacts on family and social relationships; increased risk of suicide; decreased work performance and commitment; and increased aggressiveness and use of force incidents (Carleton et al., 2018; Santa Maria et al., 
2019; Shane, 2010; Velazquez and Hernandez, 2019). Abuse of force or neglect of duty can lead to reduced public trust and police legitimacy; increased tension between the public and the police; and psychological or physical injury, including fatalities (Violenti et al., 2017).

Literature examining the impact of organizational culture, demographic relationships, and effective ways to reduce stigma is limited in policing and work scholarship more generally (Hanisch et al., 2016; Rose and Unnithan, 2015; Velazquez and Hernandez, 2019). Effectiveness of current programs and resources; ways to increase help-seeking; and better supports for those who do, are additional areas of interest (Carleton et al., 2018b; Fielding et al., 2018). A need for more qualitative research to better understand the nuances of officers' perceptions and experiences of mental illness, has been recognized (Bell and Eski, 2016; Soomro and Yanos, 2019). This study seeks to address multiple research gaps through examining how organizational culture and structure fosters stigma, thereby limiting reporting and treatment of mental illness in policing.

\section{Literature Review}

The focus of research on mental health in policing is generally divided into two areas: operational stressors (e.g. occupational-related tasks, traumatic events) and organizational stressors (e.g. organizational culture, policies and procedures, leadership) (Shane, 2010). Organizational stressors are thought to be a greater source of police stress; however, research in this area is limited (Turner and Jenkins, 2019; Violenti et al., 2017). Organizational culture has a powerful influence on the attitudes and behaviours of employees (Schein, 2010). Organizations can develop their own identities that filter down through generations of workers through the process of assimilation (Schein, 2011). Subcultures often exist within the same culture and can overlap in conflicting ways. Organizations that involve intense work environments such as policing often develop strong organizational cultures to deal with the pressures of their work. Within male-dominated work, workplace cultures with high levels of traditional masculinity are often reported (Boettcher et al., 2019).

\section{Traditional masculinity and male-dominated work}

In Western culture the definition of traditional masculinity commonly refers to a set of characteristics that emphasize stoicism, toughness, competitiveness, and self-reliance (Addis et al., 2016; Connell, 2012). Masculinity can differ by culture, time, and place and is associated with the social construct of being a man, rather than one's biological sex, meaning women can also perform masculinity (Connell and Messerschmidt, 2005). Masculine norms and expectations are learned through social interactions and are transmitted at the interpersonal, institutional, and structural levels (Addis et al., 2016; Connell, 2012). Those who do not perform the socially acceptable level of masculinity assigned to their gender are often subjected to a stigmatization process, frequently leading to social and professional consequences (Hanisch et al., 2016). These norms are often systemically entrenched in workplace cultures and structures making them difficult to recognize and change.

Paid employment remains an important predictor of status, identity, and good mental health, particularly for men (Roche et al., 2016). In male-dominated work, the organizational culture 
often requires overt displays of traditional masculinity, such as competitiveness, aggression, emotional control, and an over-commitment to the organization (Boettcher et al., 2019). Traditionally feminine traits such as displays of emotion are often viewed as weakness, and therefore, incompetence (Connell, 2012). Thus, social pressure and fear of stigmatization can create an atmosphere that upholds traditional masculinity in male-dominated workplaces (Boettcher et al., 2019). Men's mental health is particularly impacted in these types of high strain occupations, especially when low levels of job control, a lack of workplace support, and high levels of organizational injustice, are present (Roche et al., 2016).

\section{Stigma: self and structural}

Mental illness remains a socially stigmatized health condition, often associated with labels such as dangerous, deviant, unreliable, and incompetent (Link and Phelan, 2001). Erving Goffman (1963) described stigma as relational - an individual sees themselves through a lens set by the social world around them. They internalize acceptable social norms and judge themselves based on how well they fit. If they do not meet this standard, the anticipation of stigmatization by others (public stigma) leads to self-stigmatization (Goffman, 1963). Corrigan and colleagues (2004; 2009) further elaborated on how prejudices and stereotypes applied to a subgroup filter down to the individual as a form of self-stereotyping. This labelling process has a powerful influence on an individual's conception of the self (Link and Phelan, 2013). Self-stigmatization can lead to a vicious cycle of lower self-esteem and confidence, increased shame and isolation, and loss of status and opportunity in multiple aspects of one's life, including employment (Corrigan et al., 2009; Link and Phelan, 2013).

Structural stigma (or system-level), is the process of how institutional policies and procedures can perpetuate stigma towards a group, creating instances of discrimination at both personal and professional levels (Bos et al., 2013). These processes may be unintentional, but the impact further stigmatizes individuals, creating conditions that hinder their recovery (Corrigan et al., 2009). Ricciardelli et al. (2020) found evidence of structural stigma in policing, exacerbated by higher workloads and officer burnout. Officers in this study were more likely to believe mental illness was evidence of one's inability to cope in the role or as a mechanism to get time off. This negatively impacted relationships, further isolating members and potentially damaging their careers. Turner and Jenkins (2019) also found evidence of structural stigma in policing, manifested by officers' belief that organizational support for officer mental health was mere "window dressing." This led to low levels of trust in the organization, impacting officers' willingness to report symptoms.

\section{Police organizational culture and structure}

Traditional masculinity has a strong role to play in officers' perception of stigma towards mental illness in their workplace. Policing is a male-dominated occupation with a strong sense of identity attached to the role (Bikos, 2016; Brown et al., 2019). Labels such as 'unreliable', 'lazy', 'faking it', 'weak', and 'incompetent' are commonly used to describe officers' perceptions of the attitudes toward mental illness in their workplace (Bell and Eski, 2016; Velazquez and Hernandez, 2019). Fear of social and professional implications such as the loss of 
their firearm, career opportunities, and the dreaded label of 'weak,' remains high (Karaffa and Koch, 2016). This fear has merit with reports of negative impacts on employment opportunities and peer relationships by officers who experienced mental illness (Bulloch and Garland, 2017). The implementation of programs to alter systemic cultural attitudes toward mental illness has been largely insufficient (Ricciardelli et al., 2020). Part of the barrier is the lack of institutional acknowledgment regarding the significant impact police organizational culture has on attitudes and behaviours and policies and procedures (Cummins and King, 2017).

Paramilitary, hierarchal, chain-of-command workplace structures with an authoritarian style of leadership have been associated with poorer mental health outcomes (Santa Maria et al., 2019). This type of organization leaves little room for flexibility, autonomy, innovation, or open communication (Shane, 2010). Additionally, a lack of understanding and empathy from supervisors, pressure to return to work, and navigating workplace policies and procedures can retraumatize officers, prolonging their healing (Bell and Eski, 2016; Fielding et al., 2018). Witnessing these types of occurrences may influence other officers' willingness to report their symptoms. A supportive, open, and fair working environment increases employee wellbeing and may reduce stigma (Roche et al., 2016). Thus, organizational culture, structure, and leadership response must be attended to simultaneously in order to effectively address workplace mental illness (Santa Maria et al., 2019; Sarver and Miller, 2014).

Demographics such as gender, rank, and years on the job are areas researchers have identified as limitations in our understanding of the persistence and impact of stigma in the workplace (Hanisch et al., 2016; Rose and Unnithan, 2015; Soomro and Yanos, 2019). Additionally, little is known about which programs are most effective for meaningful and long-term change of attitudes and behaviours (Carleton et al., 2018b) but some promise has been found in education and awareness (Krakauer et al., 2020). Knaack et al. (2019) found that organizational structure in conjunction with cultural buy-in were necessary to change attitudes and behaviours toward mental illness and help-seeking. Police culture and leadership attitudes have been identified as significant barriers to meaningful organizational change (Duxbury et al., 2017). However, there is some evidence that the culture may be in flux, divided by officers who are ready for change and those who are not (Brown et al., 2019).

To examine the role of organizational culture and stigma in shaping mental health attitudes and behaviour in policing, this study asks the following questions: What features of the workplace culture and organizational structure do officers' report as barriers to stigma reduction in their workplace? Does gender, rank, and years of service impact officers' perception of stigma and comfort level reporting mental illness to their employer?

\section{Methods}

Due to multiple research gaps, this exploratory study uses a mixed methods approach of semistructured interviews (116 from 31 police services across Canada) and an on-line, self-report survey $(\mathrm{N}=727)$ to provide a preliminary, general overview of Canadian police officers' perceptions and experiences of stigma toward mental illness in their workplace culture. 


\section{Interviews}

Phase one of data collection included 116 in-depth, semi-structured interviews with officers from 31 police services across Canada from 2015-2019. Interviews were conducted in person, via Skype/Facetime or telephone, depending on geographic location and comfort level of the participant. Participants include 40 men and 76 women, rank levels from constable to chief, and years of service from 1 - 37 years. Participants range from active duty, on-leave, and recently retired: 21 interview participants were on medical-related leave and 15 had retired/resigned with mental illness experience.

Interviews were conducted using the principles of Charmaz's (2014) constructivist grounded theory. The conversational, semi-structured style offered flexibility to explore varied lived experience with enough structure to ensure common themes were addressed. Interviews lasted approximately one to three hours. Police can be a notoriously hard group to study, particularly when asking questions of a personal nature (Turner and Jenkins 2019). The author's status of former police officer allowed for a level of trust that facilitated access, which is why convenience and snowball sampling were chosen as recruitment methods. Initially, fifteen researcher contacts from various police services were invited to participate via email. These contacts then shared the study information in their networks. Additionally, several police academics shared the study invitation with their networks; media attention led to more contacts on a national level.

\section{Survey}

Phase two of data collection was a self-report, online survey created through the platform Qualtrics (available February to December 2019) to explore common interview themes on a larger scale. In mixed methods, the use of two sequential data sets, with the secondary data set featuring as the supporter of the more prominent data set (in this case interviews), is an acceptable practice (Creswell, 2009). This technique is also known as Triangulation, which increases the validity of research findings (Hesse-Biber, 2017). While not generalizable, the survey provides additional evidence on the extent to which issues raised by interview participants were experienced by other officers as well. Thus, the data sets together allow for a more robust exploration of commonly reported themes. Key questions touched on officers' workplace culture and were answered on a five-point Likert scale (see Tables II/III for the survey questions).

Since no sampling frame was accessible, the survey was distributed via police unions, related groups, and social media. The survey was sent to police unions and police-related groups across the country (except for Quebec), with the request to disseminate it to their members. The survey was also promoted via social media. Due to reliability and validity issues with social media recruitment, a separate link was created allowing for answer comparison with invited participants. No notable differences were found. The total survey population is $\mathrm{N}=727$ after removing cases with no answers recorded, spam responses, and responses that appeared suspicious (e.g. repeats and patterns with a minimal response time or those with odd text entries). 
Since it is not known how many officers received the survey via their unions and social media, it is impossible to calculate a response rate.

\section{Table I. Survey Demographics}

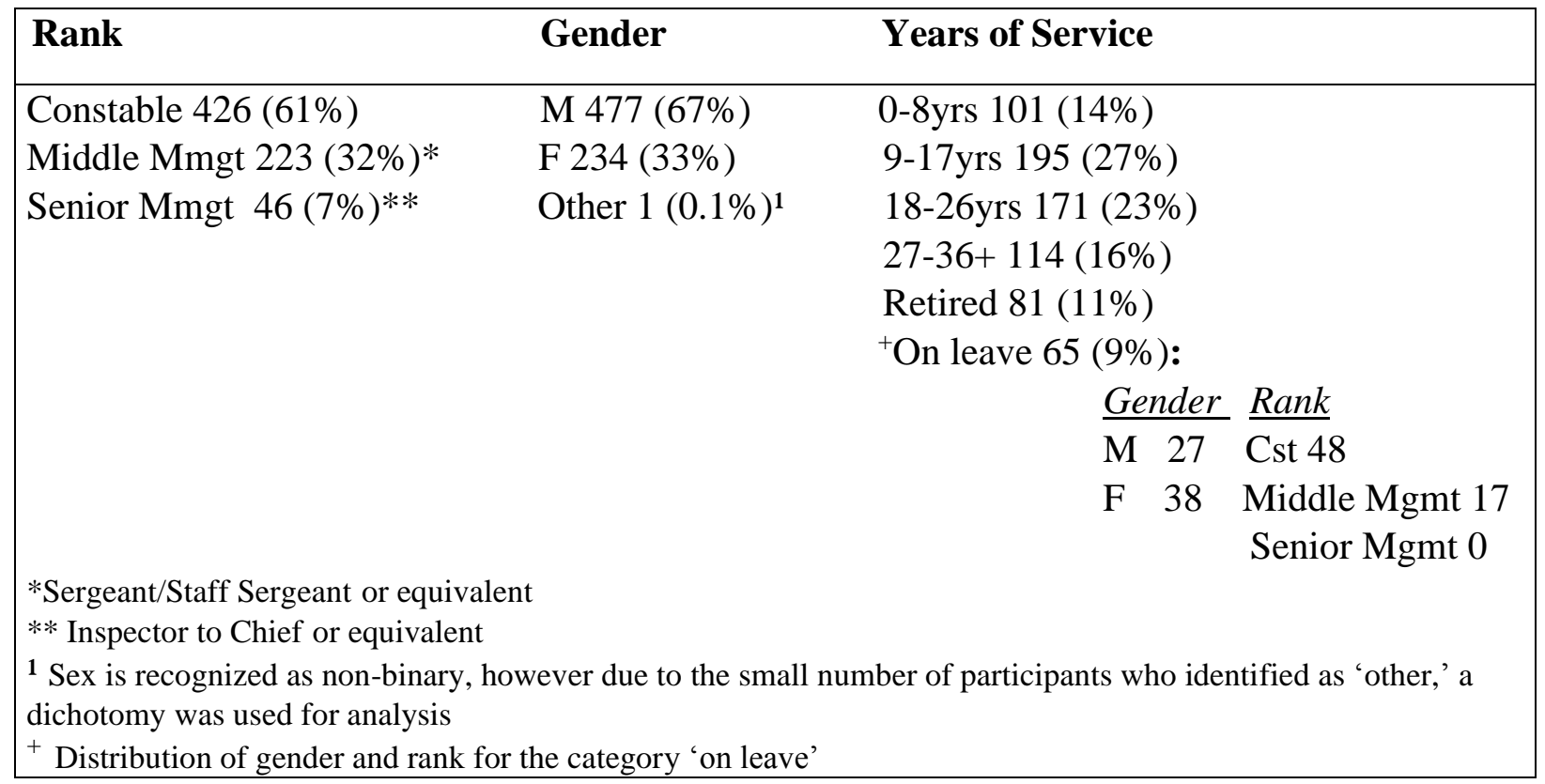

\section{Analysis}

Field notes were kept after interviews in order to reflect, track themes, and adjust questioning as required. Interviews were transcribed and uploaded into the computer program, NVIVO, to code and classify the data. First, interview transcripts were read in their entirety. Open coding followed, which included memoing and comparing previously recorded themes from field notes (Charmaz, 2014). For the purposes of this study, a concentration on themes relating to mental health and stigma were applied. This process revealed common themes such as culture and traditional masculinity, leadership attitudes and behaviours, reporting and help-seeking, and organizational response. Finally, focused coding was conducted to better understand each theme in its entirety and any relationships between themes (Hesse-Biber, 2017). Because of the researcher's status as a former policewoman, reflection practices were applied throughout the project to mitigate bias (Charmaz, 2014).

Bivariate descriptive statistics in the form of crosstabulations with a Chi Square statistical measurement were used to explore relationships. The variables of gender, rank, and years of service were chosen because of their recognition in the literature as limited areas of knowledge. The survey category 'on-leave' consists predominantly of officers with lived experience of mental illness. Table I breaks down the distribution of this category by rank and gender. A note on gender: in the interviews, when participants were asked to identify their gender, they responded using "male" or "female," understood in literature on gender as identifiers of sex. When creating the survey, the decision was made to use their language for continuity. 


\section{Results}

Interweaving interview and survey findings, this section will discuss how organizational culture and structure contribute to the persistence of stigma toward mental illness in policing, despite organizational messaging and programs aimed at its reduction.

Table II. Officers Perception of Stigma

Stigma toward officers' experiencing mental health has greatly improved in my workplace culture (somewhat/strongly agree)

\begin{tabular}{|c|c|c|}
\hline Gender* & Rank* & Years of Service* \\
\hline$(54 \%)$ & Constable (41\%) & $0-8(56 \%)$ \\
\hline \multirow{5}{*}{ Female $(37 \%)$} & Middle Management (59\%) & $9-17(46 \%)$ \\
\hline & Senior Management (68\%) & $18-26(51 \%)$ \\
\hline & & $27-36+(58 \%)$ \\
\hline & & On-leave (21\%) \\
\hline & & Retired (50\%) \\
\hline
\end{tabular}

*P<.001

\section{Organizational culture and self-stigma}

When asked whether they agreed or disagreed with the statement 'Stigma toward officers experiencing mental health has greatly improved in my workplace culture,' $48 \%$ of officers agreed. Perceptions varied by gender, rank, and years of service with women, constables, and those in the 9-26-year range less optimistic that stigma in their workplace culture had improved. Of note is the category 'on-leave,' made up predominantly of officers with lived experience related to mental illness. This group reported significantly higher perceptions of stigma in their workplace than those in other years of service categories (see Table II).

Interviews provided more nuance and context. When asked if stigma toward mental illness had improved, the majority indicated it remained at moderate-to-high levels in their workplace culture. No one indicated stigma had been eliminated and those with lived experience were most likely to believe in its prominence. Some participants indicated there was improvement from past decades, for example, an increased awareness of mental illness and more resources. Generational change was discussed by some, however many believed that stigma was embedded in their workplace, influencing new officers over time which reproduced persistent cultural barriers:

In the 80s no one talked about stress or PTSD, so stigma has changed in that way. We are more aware than before. But even today, they are very reluctant to really deal with it. They say the words, but they don't really believe it. Like everything else, oh we have this policy and stress reduction, our members are encouraged to seek psychological help bullshit. The stigma is still huge - people are afraid because of their careers and relationships and they are right to be afraid, there are real consequences. The fact of the matter is, senior management doesn't really buy into it; the new kids might be, but they aren't senior yet and they get influenced by the culture over time. Maybe in the next 
generation stigma will change, but not now. Honestly? Probably not ever if things stay the way they are. (Male, Constable, 30 years, retired early with mental illness)

\section{The role of traditional masculinity}

In interviews, traditional masculinity was often identified as the largest cultural barrier to the reduction of stigma. Table II findings reveal men were more positive about the reduction of stigma than women (54\% vs $37 \%$ ), but men in interviews spoke most frequently about the intense cultural pressure they felt to uphold features of traditional masculinity. They emphasized the need to be tough, stoic, and self-reliant:

We need to attack the shame and stigma, that "suck it up" mentality is so harmful. The mental health issues are so tied to the culture, this idea of being strong, being a man, not showing emotion. (Male, Constable, 17 years, resigned early with mental illness)

They'll tell you there's no stigma. It's an outright lie. You've got to present the persona of being indestructible or your career is over. (Male, Constable, 28 years, active duty)

Features of self-stigmatization were frequently revealed in interviews by both men and women; however, men deeply internalized the idea that mental illness reflected weakness, and therefore, incompetence. The result was often avoidance and/or intense feelings of shame, which greatly impacted their self-esteem and self-efficacy:

What does PTSD or stress in first responders look like? It's ugly... a level of humiliation in policing that unless you've been through it you can't understand it. (Male, Constable, 20 years, on-leave)

Part of combatting stigma is that things like PTSD are underreported because cops don't want their careers to be ruined, they don't want to be ridiculed, they don't want their gun taken. People don't understand that getting your gun taken is like death - it is part of what you are. (Male, Constable, 20 years, on-leave)

Somewhere in my heart and mind I will always see this as a form of weakness. Til the day I die, it will always feel that way just a little bit. I failed as a cop. I couldn't deliver. That's a huge part of the shame. (Male, Constable, 19 years, on-leave)

\section{Structural stigma: the intersection of culture and organizational structure}

Overall, interviews revealed that leadership attitudes and behaviours were the most common ways that organizational culture and structure combined, creating barriers to stigma reduction. The cultural stigmatization of mental illness as "incompetent" or 'working the system' was often reported as a top-down feature, influencing organizational response to mental illness:

Is stigma still there systemically? Yes, absolutely. At least once a week I get an email from someone and I am appalled by management response - things like denying them sick days, saying they don't believe them - they just want paid time off, trying to order them back to work early... I thought that things would have gotten better, but in some quarters, it is still just awful. (Male, middle manger, 18 years, active duty) 
Similar to interview findings, a significant disconnect between ranks was identified in survey responses. Senior management's belief that stigma in the workplace culture had improved was almost 30\% higher than constables (see Table II). Middle management was less likely to agree than senior management but were still more positive overall. In interviews, the feeling of 'window dressing' rather than genuine concern for employees was a common theme at the constable or middle management level. The following quotes reveal the often reported disconnect between ranks, influencing officer attitudes, most notably in their lack of trust in senior management's sincerity:

They pretend there's empathy and compassion. The Chief tweets out this mental health awareness bullshit everyday and they wear their pink bullying shirts. They put up some bullshit posters around the station for us to look at. They encourage us to report and use the resources available. It's all fucking window dressing. I don't believe it for a second. We're just a number that becomes a liability the second we admit we need help. I've seen it too many times. We all have. (Male, Constable, 12 years, active duty)

I remember after one horrible suicide, my Inspector calls and says, "Make sure you offer your shift EAP so we can say we did it." And I'm thinking "So we can say we did it?!" Are you just checking off a box? What about our people's health? The policies are there, but they're just worried about liability. So sure, we offer resources, but do we do that in a genuine way? What kind of message does that send to our members about how the service really views mental health? Look at me, I didn't report for years because I got the message it wasn't really acceptable. (Male, middle manager, 30 years, active duty)

Senior leaders were not represented in the 'on leave' survey category (see Table I), but they were represented in the interview sample. Some senior managers believed their workplace was doing a good (albeit with room for improvement) job breaking down barriers, educating officers, and providing resources. However, other senior managers believed that meaningful progress had not been made, discussing how cultural expectations of traditional masculinity were embedded in leadership attitudes, impacting policy adherence and progressive policy formation:

Some of the conflicts I had with peers were about the management of critical stress incidents. There are very clear guidelines around it that are not being followed. For example, I was arguing with a couple of male supervisors that we should have new policy made to be more proactive and approach members we felt had experienced critical incident stress, meaning they didn't have to seek us out. Their response was "you're going to turn them into pussies." I mean, that says it all. There are policies in place for mental health but there is this pervasive culture that guys should be tough and just deal with seeing this stuff everyday. Well, newsflash, people are killing themselves. It's ugly, there is so much stigma and it hinders us from moving forward. (Female, senior manager, active duty, 22 years)

Resources, programs, and training to combat stigma and encourage officers to seek help were common interview themes. The majority felt these had not been successful in meaningfully 
reducing stigma in their workplace environment because they had failed to be fully embraced culturally from the top-down:

We have all the programs that you could get. We have Road to Mental Readiness. I was part of the initiation of the Critical Incident Stress Management and Peer Support teams. Honestly, it's all just window dressing. I had one member about to commit suicide at the end of last year. I bring it upstairs and say, "I don't know what to do to help them." The Chief didn't like this officer, blamed them and did nothing. So, I've seen it firsthand - we have everything we need but we don't have buy in from the top and therefore, it's not trickling down. (Female, middle manager, 17 years, active duty)

The impact: reporting mental illness?

The impact of cultural and structural stigma was the strong belief that reporting mental illness came with significant risk of career and/or social repercussions (See Table III).

Table III. Police Officers' Perception of Risk to Report Mental Illness

\begin{tabular}{|c|c|c|c|c|}
\hline Gender** & Rank* & & \multicolumn{2}{|c|}{ Years of Service* } \\
\hline \multicolumn{5}{|c|}{ I would report mental health to my service without fear of career or social repercussions (24\% agree) } \\
\hline Male $\quad 27 \%$ agree & Constable & $19 \%$ agree & $0-8$ & $24 \%$ agree \\
\hline \multirow[t]{5}{*}{ Female $20 \%$ agree } & Middle Mgmt & $29 \%$ agree & $9-17$ & $23 \%$ agree \\
\hline & Senior Mgmt & $44 \%$ agree & $18-26$ & $25 \%$ agree \\
\hline & & & $27-36+$ & $38 \%$ agree \\
\hline & & & On leave & $13 \%$ agree \\
\hline & & & Retired & $16 \%$ agree \\
\hline
\end{tabular}

Note: results reported from combined somewhat/strongly agree categories

$* P<.001 * * P<.05$

Similar to Table II, gender, rank, and years of service were statistically significant when measuring officers' perception of risk in relation to reporting mental illness. Overall, $24 \%$ of officers agreed they would report mental illness to their employer without fear of career or social repercussions. Women, constables, and those on leave were most likely to perceive professional and social risks. A disconnect in rank was again prominent, with senior management more likely to agree they would report mental illness without fear.

In interviews, officers who had reported mental illness were overwhelmingly at the constable level (with some middle managers). These officers revealed stigmatization by supervisors, compounded by policies and procedures that disadvantaged them. The interplay of cultural norms and organizational structure created toxic conditions of avoidance, harassment, and othering that put officers at additional psychological risk: 
I have only had one supervisor who asked me if I was okay. Others would either discipline me for stupid shit or ridicule me in front of other officers. You sit there and you try to laugh it off and act like the comments didn't bother you but inside you want to cry. They rode me about performance even though they all knew I was experiencing mental health issues. They were really insensitive to what I was going through. The damage that did to me really set me back. (Male, Constable, 20 years, on-leave)

They didn't know what to do with me, so they just kept sending me out on the street. I can think of at least a dozen people who should be off the street right now and there's no way their supervisors don't know. Or maybe they don't. I guess you can fit in pretty well with PTSD, which is a disturbing thing to say but honestly my behaviour fit in pretty well with a lot of my co-workers...I basically looked dead. The signs were all there, but they just wanted to ignore it. It was just like, here is your EPA number. But they are not trained for PTSD so that was useless. (Male, Constable, 15 years, on-leave)

Interviews revealed that social and career implications were more than mere perception, with some participants witnessing the limited career opportunities and cultural ostracization officers faced on their return to the workplace:

The leaders of our region need a lot more education about how to help our members who have healed get back into the job. The mindset is still very narrow and ignorant. Officers can come back and be on the front line again, we don't just have to shove them into headquarters and things unless that's what they want. That doesn't help the stigma. We need more education on what to do when officers come back and listen to them and their needs. (Male, middle manager, 30 years, active duty)

Even some of the people who have been off with mental health or addiction issues, when they come back, they are treated horribly. People don't give them a chance; they get ostracized. If you come back to work after a mental health issue and no one wants to know you or work with you - how do you get healthy? Who is going to willingly report after seeing stuff like that? (Female, Constable, 13 years, active duty)

Most officers who reported mental illness described problematic behaviour by their management team and service policies that further stigmatized them, adding additional trauma which significantly impacted their recovery. These officers often resigned early or were on lengthy sick leaves, with a low desire to return to a workplace they viewed as a significant risk to their overall wellbeing:

I was proactive in my healing, doing the counselling and getting better. Being away from there was really good for me. My doctors told them I wasn't able to come back yet. The service starts to get mad that I've been off so long and starts fighting me about my time off and pay. The result was that I no longer had agency over who my doctors would be, what programs I was involved in, and they were pushing me back to work. I went to my association, no help there. I hired my own lawyer and have to pay for it myself while I'm on disability. The process was humiliating. I had to drop my treatment to participate in theirs which was not set up to deal with police-related PTSD. But I had no choice. I have 
bills to pay so I have to go along with it, but it set me back years - I had been doing really well. (Male, middle manager, 10 years, on-leave)

\section{Discussion}

Policing in Canada remains male-dominated with varying levels of traditionally masculine features within its occupational culture (Bikos, 2016; Langan et al., 2019; Statistics Canada, 2019). These features are linked to higher rates of stigma toward mental illness and lower rates of reporting (Knaack et al., 2019; Stuart, 2017). In the current study, approximately half of those surveyed agreed stigma had improved in their workplace culture (Table II). In interviews, officers acknowledged there was more awareness, acceptance, and programs aimed at the reduction of stigma toward mental illness than in the past. While this is good news, it must be taken with caution as 'improvement' in this study did not necessarily mean significant change. Most officers reported moderate-to-high levels of stigma toward mental illness in their police service and a high perception of risk in relation to reporting mental illness.

In interviews, traditionally masculine traits such as being tough, stoic, and self-reliant were often synonymous with competent, worthy, and respect. The belief that those who experience mental illness are labelled weak, incompetent, and lazy largely remained, despite senior management messaging and programs/resources. These perceptions led many to internalize labels and stereotypes in a process known as self-stigmatization (Goffman, 1963; Corrigan, 2004). This internalization often manifested through intense feelings of shame, self-doubt, and lower selfesteem, solidified by the social and professional rejection of peers and supervisors. These results are consistent with Link and Phelan's (2001) description of how stigma can 'other' some from the dominant group, leading to status loss, rejection, and discrimination. Women in the survey reported a much higher belief in the existence of stigma than men, but men in interviews reported higher rates of avoidance and self-stigmatization. Both men and women reported similar rates of fear in regard to reporting mental illness (Table III). In-depth qualitative inquiry examining the role of gender is needed to better understand cultural features and impacts.

Similar to Ricciardelli et al. (2020) and Turner and Jenkins (2019), this study found high levels of structural stigma, most notably in how cultural assumptions of mental illness intertwined with organizational structure. This presented in leadership attitudes/behaviours and

policies/procedures that often targeted, isolated, and blamed the individual; a common feature of structural stigma in the workplace (Bos et al., 2013). A significant disconnect was found amongst ranks, with constables (and middle management to some degree) much more likely to believe stigma remained at harmful levels. Interviews offered insight into the disconnect, with constables and middle management often reporting the perception (and in some cases, experience) of a lack of genuine care by senior leaders, despite organizational messaging and resources. Additionally, only $24 \%$ of officers surveyed agreed they would report mental illness without fear, leaving $76 \%$ who did not agree. Constables were more likely to perceive risk, but more than half of senior leaders also feared the impact of reporting mental illness (Table III). In interviews, almost all who did report describe experiences of professional and personal harm, adding evidence that officers' perceptions of risk have merit. 
Interviews revealed there were leaders who tried to demonstrate empathy and create progressive policy, but they ran up against a bigger wall - the organizational culture. Thus, there are progressive and innovative thinkers in policing, but they remain outnumbered, particularly in spaces of power where change can be made. A more thorough investigation into the perceptions and experiences of senior leadership is warranted, given their position of power. Longitudinal and qualitative research would be informative in this context.

In both interviews and survey results, those with lived experience reported the highest belief in persistent stigma and risk in relation to reporting mental illness to their service. Their experiences reveal important gaps in achieving officer wellness, including evidence of further psychological harm from leadership attitudes/behaviours and structural policies/procedures. Interview findings revealed officers were sent out for active duty and/or pushed back to work early, despite clear signs they were not healthy. This poses potentially serious risks to officers and the public. More research with officers who are on leave, retired, or resigned due to mental illness should be conducted. The fact that this group is not consulted by their services adds another example of ways stigma toward those with mental illness may be embedded in the institution.

While some progress has been made, these results suggest that progress has been incremental and uneven. Most participants were skeptical about the impact programs and resources had made in the reduction of stigma in their service to-date. Evidence of systemic and structural stigma were found in leadership attitudes/behaviours and policies/procedures, which heavily impacted officers' beliefs that stigma toward those with mental illness in their workplace remained. The overall impact was a high level of belief that reporting mental illness poses significant risks. These findings indicate that while some senior leadership may have genuine intentions to reduce stigma and foster an environment where officers will seek help, a much deeper and honest review of organizational culture and its impacts on the workplace must be done.

\section{Limitations}

Despite the relatively close proportion of demographic representation in Canadian policing (see Statistics Canada, 2019), this study cannot be considered representative of all officers' experiences. There is the potential for a selection effect due to recruitment methods. However, the study provides mixed methods data with various demographic features. Comparisons of interview and survey data reveal common themes and trends suggesting the data are valid and reliable.

Officers may have been motivated to participate in this study due to experience, potentially skewing the data and explaining the high reports of the perception of stigma and risk. However, these findings are consistent with a recent Canadian study which found $85 \%$ of officers believed most officers did not report mental illness; $62 \%$ believed those that did experienced discrimination; and 59\% saw mental illness as a personal failure (Stuart, 2017).

Lastly, the researcher is a former police officer with preconceived biases. Methods such as journaling reflections, semi-structured interviews, tracking and comparison of themes, shifting 
questions as new themes emerged, seeking participants of varied experience, and a mixed methods design (Triangulation), were mechanisms used to mitigate the impact of bias.

\section{Conclusion}

In a period of increasing stress due to higher workloads, increased public scrutiny, and a rapidly changing social world, it is likely to assume officer mental health will be negatively impacted. Heightened conditions of stress mean more incidents of mental illness which left untreated, have multiple poor outcomes. Effective education to increase awareness and buy-in (beginning with leadership); social support from peers and leaders; effective resources that are confidential and police-specific; policy and procedures that normalize mental illness as a job hazard, not a personal failure; ongoing communication; and integrative return-to-work policies are solid first steps to addressing persistent stigma toward mental illness. These initiatives should be implemented simultaneously and overseen by external experts. This study's findings reveal that significant efforts should be made to understand how to shift traditional masculinity in police culture. Given its impact on officer wellness and help-seeking behaviour, culture should not be taken lightly for the health and safety of both the pubic and the police.

\section{Acknowledgments}

My sincere gratitude to Ph.D. supervisor, Dr. Tracey Adams for her support and guidance and Sergeant Dave Gilmore, President of the London Police Association for his support and invaluable assistance with the on-line survey. Thank you to the anonymous reviewers whose helpful feedback improved this manuscript.

\section{Corresponding author}

Lesley J. Bikos can be contacted at: lbikosresearch@gmail.com

\section{References}

Addis, M.E., Reigeluth, C.S., and Schwab, J.R. (2016), "Social norms, social construction, and the psychology of men and masculinity", APA handbook of men and masculinities, pp. 81-104.

Bell, S., and Eski, Y. (2016), “'Break a Leg - It's all in the mind': Police Officers' Attitudes towards Colleagues with Mental Health Issues", Policing: A Journal of Policy and Practice, Vol. 10 No. 2, pp. 95-101.

Bikos, L.J. (2016), “"I took the blue pill”: The effect of the hegemonic masculine police culture on Canadian policewomen's identities", MA Research Paper, ir.lib.uwo.ca/sociology_masrp/7.

Boettcher, N., Mitchell, J., Lashewicz, B., Jones, E., Wang, J., Gundu, S., Marchand, A., Michalak, E. and Lam, R. (2019), “Men's Work-Related Stress and Mental Health: Illustrating the Workings of Masculine Role Norms", American Journal of Men's Health, Vol. 13 No. 2, doi.org/10.1177/1557988319838416. 
Bos, A.E.R., Pryor, J., and Reeder, GD. (2013), "Stigma: Advances in theory and research", Basic and Applied Social Psychology, Vol 35, pp. 1-9.

Brown, J., Fleming, J., Silvestri, M., Linton, K. and Gouseti, I. (2019), “Implications of police occupational culture in discriminatory experiences of senior women in police forces in England and Wales", Policing and Society, Vol. 29 No. 2, pp. 121-136, doi.org/10.1080/10439463.2018.1540618.

Bullock, K., and Garland, J. (2017), "Police officers, mental (ill-) health and spoiled identity", Criminology \& Criminal Justice, Vol. 18 No. 2, pp. 173-189.

Carleton, R.N., Afifi, T.O., Turner, S., Taillieu, T., Duranceau, S., LeBouthillier, D.M., Sareen, J., Ricciardelli, R., MacPhee, R.S., Groll, D., Hozempa, K., Brunet, A., Weekes, J.R., Griffiths, C.T., Abrams, K.J., Jones, N.A., Beshai, S., Cramm, H.A., Dobson, K.S., Hatcher, S., Keane, T.M., Stewart, S.H. and Asmundson, G.J.G. (2018a), "Mental disorder symptoms among public safety personnel", Canadian Journal of Psychiatry, Vol. 63 No. 1, pp. 54-64.

Carleton, R.N., Korol, S., Mason, J.E., Hozempa, K., Anderson, G.S., Jones, N.A., Dobson, K.S., Szeto, A. and Bailey, S. (2018b), "A longitudinal assessment of the road to mental readiness training among municipal police", Cognitive Behaviour Therapy, Vol. 47 No. 6, pp. 508-528, doi.org/10.1080/16506073.2018.1475504.

Charmaz, K. (2014), Constructing Grounded Theory, Sage Publishing, Thousand Oaks, CA.

Connell, R. (2012), "Gender, health and theory: conceptualizing the issue, in local and world perspective”, Social Science \& Medicine, Vol. 74, pp. 1675-1683.

Connell, R.W. and Messerschmidt, J.W. (2005), "Hegemonic masculinity: rethinking the concept", Gender and Society, Vol. 19, pp. 829-859.

Corrigan, P.W. (2004), "How stigma interferes with mental health care", American Psychologist, Vol. 59, pp. 614-625.

Corrigan, P.W., Larson, J.E., and Rusch, N. (2009), "Self-stigma and the "why try" effect: impact on life goals and evidence-based practices", World Psychiatry, Vol. 8 No. 2, pp. 75-81.

Creswell, J.W. (2009), Qualitative, Quantitative, and Mixed Methods Approaches, Sage Publishing, Thousand Oaks, CA.

Cummins, I., and King, M. (2017), “'Drowning in here in his bloody sea': exploring TV cop drama's representations of the impact of stress in modern policing", Policing and Society, Vol. 27, pp. 832-846, doi.org/10.1080/10439463.2015.1112387.

Duxbury, L., Bennell, C., Halinkski, M., and Murphy, S. (2017), "Change or be changed: Diagnosing the readiness to change in the Canadian police sector", The Police Journal: Theory, Practice, Principles, Vol. 91, pp. 316-338. 
Fielding, N.G., Bullock, K., Fielding, J.L., and Hieke, G. (2018), "Patterns of injury on duty and perceptions of support amongst serving police personnel in England and Wales", Policing and Society, Vol. 28, pp. 1005-1024, doi.org/10.1080/10439463.2017.1374386.

Goffman, E. (1963), Stigma: Notes on the Management of Spoiled Identity, Englewood Cliffs, New Jersey: Prentice-Hall.

Hanisch, S.E., Twomey, C.D., Szeto, A.C.H., Birner, U.W., Nowak, D. and Sabariego, C. (2016), "The effectiveness of interventions targeting the stigma of mental illness at the workplace: a systematic review", BMC Psychiatry, Vol. 16 No. 1.

Hesse-Biber, S.N. (2017), The Practice of Qualitative Research, SAGE Publishing, Thousand Oaks, CA.

Karaffa, K.M. and Koch, J.M. (2016), "Stigma, pluralistic ignorance, and attitudes toward seeking mental health services among police officers", Criminal Justice and Behaviour, Vol. 43 No. 6, pp. 759-777, doi.org/10.1177/00938548156 13103.

Knaak, S., Luong, D., McLean, R., Szeto, A. and Dobson, K.S. (2019), "Implementation, Uptake, Culture Change: Results of a Key Informant Study of a Workplace Mental Health Training Program in Police Organizations in Canada", The Canadian Journal of Psychiatry, Vol. 64 No. 1, pp. 30-38, doi.org/10.1177/0706743719842565.

Krakauer, R.L., Stelnicki, A.M., and Carleton, R.N. (2020), "Examining Mental Health Knowledge, Stigma, and Service use Intentions Among Public Safety Personnel”, Frontiers in Psychology, Vol. 11, pp. 949, doi.org/10.3389/fpsyg.2020.00949

Langan, D., Sanders, C.B., and Gouweloos, J. (2019), "Policing Women's Bodies: Pregnancy, Embodiment, and Gender Relations in Canadian Police Work", Feminist Criminology, Vol. 14 No. 4, pp. 466-487, doi.org/10.1177/1557085118763083

Link, B.G. and Phelan, J.C. (2001), "Conceptualising stigma”, Annual Review of Sociology, Vol. 27, pp. 363-385.

Link, B.G. and Phelan, J.C. (2013), "Labelling and stigma", Handbook of the Sociology of Mental Health, pp. 525-541.

Oliphant R (2016), "Healthy Minds, Safe Communities: Supporting Our Public Safety Officers through a National Strategy for Operational Stress Injuries”, Ottawa, ON, Canada: Standing Committee on Public Safety and National Security.

Ricciardelli, R., Carleton, R.N., Mooney, T., and Cramm, H. (2020), ““'Playing the system”: Structural factors potentiating mental health stigma, challenging awareness, and creating barriers to care for Canadian public safety personnel", Health: An Interdisciplinary Journal for the Social Study of Health, Illness and Medicine, Vol. 24 No. 3, pp. 259-278. 
Roche, A.M., Pidd, K., Fischer, J.A., Lee, N., Scarfe, A. and Kostadinov, V. (2016), "Men, work, and mental health: A systematic review of depression in male-dominated industries and occupations", Safety and Health at Work, Vol. 7 No. 4, pp. 268-283.

Rose, T. and Unnithan, P. (2015), "In or out of the group? Police subculture and occupational stress", Policing: An International Journal of Police Strategies \& Management, Vol. 38, pp. 279-294, doi.org/10.1108/PIJPSM-10-2014-0111.

Santa Maria, A., Wolter, C., Gusy, B., Kleiber, D. and Renneberg, B. (2019). “The Impact of Health-Oriented Leadership on Police Officers' Physical Health, Burnout, Depression and WellBeing”, Policing: A Journal of Policy and Practice, Vol. 13 No. 2, pp. 186-200.

Sarver, M. and Miller, H. (2014), "Police chief leadership: styles and effectiveness", Policing: An International Journal of Police Strategies \& Management, Vol. 37 No. 1, pp. 126-143, doi.org/10.1108/PIJPSM-03-2013-0028.

Schein, E. (2010), Organizational Culture and Leadership, 4th Edition, Jossey-Bass Publishing.

Schein, E. (2011), "What is Culture", Sociology of Organizations: Structure and Relationships, Thousand Oaks.

Shane, J.M. (2010), "Organizational stressors and police performance”, Journal of Criminal Justice, Vol. 38 No. 4, pp. 807-818.

Soomro, S. and Yanos, P.T. (2019), "Predictors of Mental Health Stigma among Police Officers: the Role of Trauma and PTSD", Journal of Police and Criminal Psychology, Vol. 34, pp. 175183, doi.org/10.1007/s11896-018-9285-X.

Statistics Canada. (2019), "Police Resources in Canada 2018", Catalogue no. 85-002-X, available at: https://www150.statcan.gc.ca/n1/pub/85-002-x/2019001/article/00015-eng.htm.

Stuart, H. (2017), "Mental illness stigma expressed by police to police", The Israel Journal of Psychiatry and Related Sciences, Vol. 54 No. 1, pp. 18-23.

Turner, T. and Jenkins, M. (2019), “'Together in Work, but Alone at Heart': Insider Perspectives on the Mental Health of British Police Officers", Policing: A Journal of Policy and Practice, Vol. 13, pp. 147-156, doi.org/10.1093/police/pay016.

Velazquez, E. and Hernandez, M. (2019), "Effects of police officer exposure to traumatic experiences and recognizing the stigma associated with police officer mental health", Policing: An International Journal, Vol. 42 No. 4, pp. 711-724, doi: 10.1108/PIJPSM-09-2018-0147.

Violanti, J.M., Charles, L.E., McCanlies, E., Hartley, T.A., Baughman, P., Andrew, M.E., Fekedulegn, D., Ma, C.C., Mnatsakanova, A. and Burchfiel, C.M. (2017), "Police stressors and health: A state-of-the-art review", Policing: An International Journal, Vol. 40 No. 4, pp. 642656, doi: 10.1108/PIJPSM-06-2016-0097. 
Bikos (2020) 18 